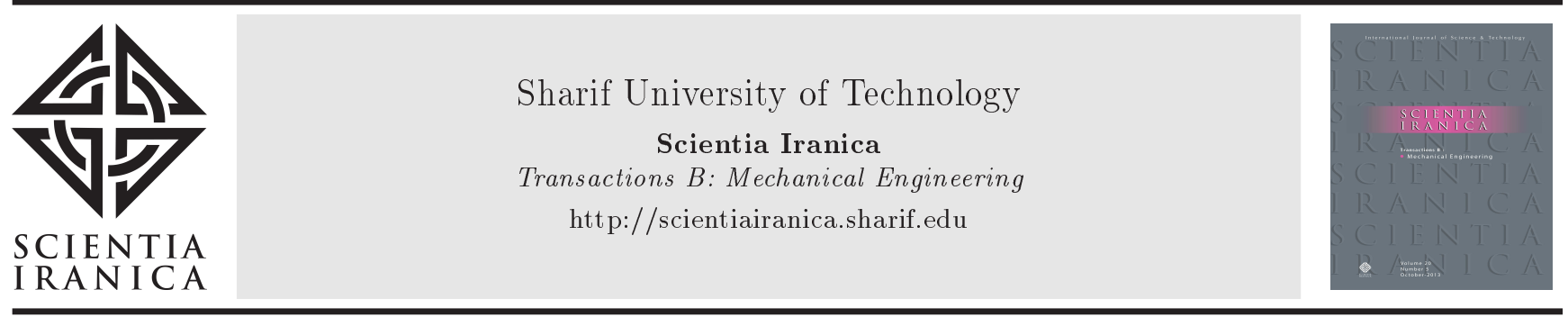

\title{
Numerical investigation of the mechanical performance of Thoracic Aortic Aneurysm (TAA) NiTi stent
}

\author{
F. Nematzadeh* and H. Mostaan \\ Department of Materials Engineering, Faculty of Engineering, Arak University, Arak, P.O. Box 38156-88349, Iran.
}

Received 21 May 2018; received in revised form 27 March 2019; accepted 20 May 2019

\author{
KEYWORDS \\ Crimping; \\ Crushing; \\ NiTi stent; \\ Thoracic Aortic \\ Aneurysm (TAA); \\ FEM.
}

\begin{abstract}
Nowadays, superelastic NiTi stent is used in Thoracic Aortic Aneurysm (TAA) because of its effective role in minimizing such problems as low twistability, unsuitable dynamic behavior, and shortage of radial mechanical strength. In the simulations, NiTi superelasticity is modeled based on Auricchio's theory and the theory of Tanaka, Liang, and Rogers. Auricchio's model is found to be more consistent with the experimental data than models of Tanaka, Liang, and Rogers. In the present study, a Finite Element Analysis (FEA) was used to evaluate the impacts of applied strain on the superelastic behavior of a novel design for TAA NiTi wire stent, for which axial strain (crushing) and radial strain (crimping) forces were applied. The results showed that NiTi stent with $50 \%$ crimping and $90 \%$ crushing exhibited the highest mechanical performance owing to suitable Chronic Outward Force (COF), appropriate Radial Resistive Force (RRF), complete mechanical hysteresis pertaining to superelastic performance, and lower stress and greater strain on the internal curvature of the NiTi stent. Finally, this Finite Element Method (FEM) can provide a convenient way for evaluating the biomechanical properties of TAA stents based on the effect of the strain applied.

(C) 2020 Sharif University of Technology. All rights reserved.
\end{abstract}

\section{Introduction}

Martensite transformation of shape-memory alloys is classified as the first-order phase transformation (diffusionless and reversible) [1,2]. Superelasticity refers to the Stress-Induced Martensite (SIM) at temperatures higher than Af temperature of $\mathrm{NiTi}$ alloy [1]. Owing to their durability, metallic implants have been widely applied to surgical operations for a long time. Nowadays, superelastic NiTi is widely used as a stent in cardiovascular treatments. Stent application has been a key solution to cardiovascular illnesses in the previous decade [2]. Endovascular repair

*. Corresponding author. Tel.: +98 8632625005;

Fax: +98 8632780801

E-mail address: f-nematzadeh@araku.ac.ir (F. Nematzadeh)

doi: $10.24200 /$ sci.2019.51077.1989 with stent grafts is an attractive method for treating cardiovascular diseases [3]. Recently, the use of NiTi stents has been developed for healing distal curvature or proximal descending aortic aneurysms and, also, for supporting frame and a polyester fabric (PTFE or polyester graft materials) owing to their superelastic behavior [4]. Z-shaped stents are commonly employed for stent designing due to their good retrievability and flexibility $[1,2]$. Given the extraordinary role of different parameters of the stent design in generating its suitable properties, analytical equations have been applied to study how the geometrical parameters of a stent are related to each other $[1,2,5,6]$.

The first numerical study about fatigue performance of NiTi stent was carried out by Whitcher [7]. Petrini et al. found good agreement between experimental and numerical results of the crushing test for NiTi stent [8]. Kleinstreuer et al. numerically investigated diverse NiTi stent-graft material combi- 
nations for auxiliary abdominal aortic aneurysm [9]. Beule et al. formulated an approach to study and improve the mechanism of braided stents [10]. Silber et al. worked on the impact of geometrical features of NiTi stents on their mechanical performance [11]. Merwe et al. considered FEA as a useful method for designing knitted NiTi meshes for use as the exterior vein reinforcement [12]. Fortier et al. summarized the accessible research studies on the biomechanical environment in healthy and diseased arteries using several analytical techniques [13]. Auricchio et al. simulated the application of a novel strategy for the apposition of a SAPIEN valve in a patient-specific aortic root model accounting for a number of periods that characterize the technique [14]. Pauck and Reddy presented a series of material tests to determine the mechanical properties of Poly-L-lactic Acid (PLLA) and used the documents of these examinations for a computational study aimed at evaluating the radial behavior of polymeric stents [15]. Jung and Kim numerically studied the effects of geometrical structures on the mechanical behavior of commercial self-expandable stents and evaluated the resulting reactions of diverse stent patterns [16]. Guerchais et al. introduced an approach to the fatigue design of balloon-expandable stents based on a micromechanical model combined with a probabilistic procedure [17]. Bressloff et al. optimized coronary artery stent design with the kriging predictor functions [18]. Altnji et al. urbanized numerous utilization simulations of parameterized stents using Finite Element Method (FEM) to evaluate the contact stiffness of a nitinol stent in a realistic Thoracic Aortic Aneurysm (TAA) employing a Coulomb friction model in a short-term stent fixation frame [19]. Nathan et al. revolutionized the treatment of superficial femoral artery by improving radial strength and incorporating shape-memory physical appearance to stimulate the recovery from crush [20]. Wang et al. studied Radial Resistive Force (RRF) of vertebral body shape-memory alloy stent based on design factors and biomechanical response using FEM and Response Surface Method (RSM) [21]. Maleckis et al. reviewed the challenges of identifying a proper stent design and provided mechanical perspectives on Femoropopliteal Artery (FPA) Nitinol-specific stent design and, also, on the characterization of the biomechanical environment of the FPA [22].

Nonetheless, a number of researchers have investigated the performance of NiTi stents [7-29]. Numerical investigations into the behavior of TAA Z-shaped NiTi wire stents have not been explored yet. The present study assesses the effect of major crimping and crushing on the mechanical behavior of TAA Z-shaped NiTi wire stents.

\section{Research methodology}

\subsection{Stent Geometry}

This study designed a Z-shaped NiTi wire stent shown in Figure 1, applied it to TAA using Catia v.5 (Dassault Systèmes, USA), and modified the FEA code. Design factors of the Z-shaped TAA NiTi wire stent, as shown in Figure 1, were extracted based on data on heat treatment of NiTi and the clinical information existing in the literature $[3,4,30]$.

\subsection{Material properties and validation of the simulation}

The present study merely attempts to compare the NiTi stents fabricated for medical applications. For simulations, Auricchio's theory is generalized in order to model NiTi superelasticity [31-37]. Factors needed in Abaqus 6.10 (Dassault Systèmes, USA) for NiTi material based on Auricchio's model are listed in Table 1 [30-39]. On the other hand, NiTi superelasticity is modeled based on the theory of Tanaka, Liang, and Rogers. EchoBio urbanized a user material subroutine based on the theory of Tanaka, Liang, and Rogers [40,41]. The properties of the materials used in simulation are given in accordance with the models proposed by Tanaka, Liang, and Rogers, as shown in Table $2[30,38,39]$. As shown in Figure 2, Table 1, and Table 2, material properties of Auricchio's theory show better consistency with the empirical information than the results of models of Tanaka, Liang, and Rogers. Therefore, Auricchio's model is employed in

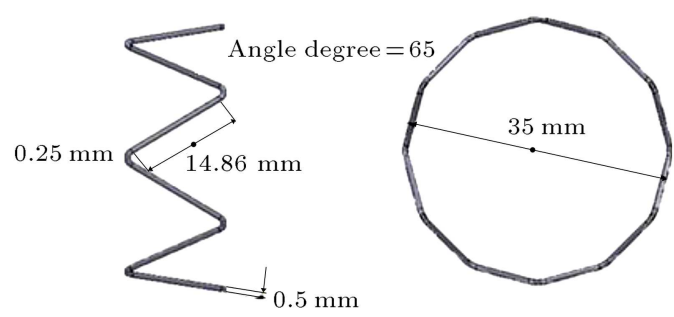

(a)

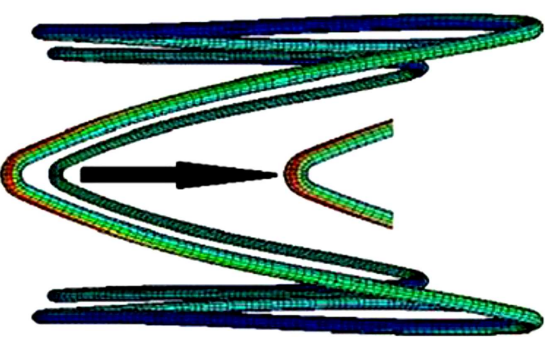

(b)

Figure 1. Designing Z-shaped NiTi wire stent for TAA application based on material properties and clinical reports [3,4,20]: (a) Geometric details and (b) exact position of the stent where computational calculations have been done (unit of length in $\mathrm{mm}$ ). 
Table 1. Material properties of the TAA NiTi stent based on Auricchio's model [20-29].

\begin{tabular}{cccc}
\hline Symbol & Description & Unit & Value \\
\hline$E_{A}$ & Austenite elasticity & $\mathrm{MPa}$ & 20700 \\
$\nu_{A}$ & Austenite Poisson's ratio & & 0.33 \\
$E_{M}$ & Martensite elasticity & $\mathrm{MPa}$ & 11700 \\
$\nu_{M}$ & Martensite Poisson's ratio & - & 0.33 \\
$\varepsilon^{L}$ & Transformation strain & - & 0.055 \\
$(\delta \sigma / \delta T)_{L}$ & Stress/temperature ratio during loading & $\mathrm{MPa} \mathrm{T}{ }^{-1}$ & 5.32 \\
$\sigma_{L}^{S}$ & Start of transformation loading & $\mathrm{MPa}$ & 344 \\
$\sigma_{L}^{E}$ & End of transformation loading & $\mathrm{MPa}$ & 363 \\
$T_{0}$ & Reference temperature & ${ }^{\circ} \mathrm{C}$ & 37 \\
$(\delta \sigma / \delta T)_{U}$ & Stress/temperature ratio during unloading & $\mathrm{MPa} \mathrm{T}{ }^{-1}$ & 5.32 \\
$\sigma_{U}^{S}$ & Start of transformation unloading & $\mathrm{MPa}$ & 58 \\
$\sigma_{U}^{E}$ & End of transformation unloading & $\mathrm{MPa}$ & 42 \\
$\sigma_{C L}^{S}$ & Start of transformation stress in compression & $\mathrm{MPa}$ & 0 \\
$\varepsilon_{V}^{L}$ & Volumetric transformation strain & - & 0.055 \\
$\varepsilon_{\max }$ & Strain limit & & 0.08 \\
$A_{f}$ & Austenite finish temperature & ${ }^{\circ} \mathrm{C}$ & 24 \\
\hline
\end{tabular}

Table 2. Material properties of the TAA NiTi stent based on models of Tanaka, Liang, and Rogers [20,28-31].

\begin{tabular}{cccc}
\hline Symbol & Description & Unit & Value \\
\hline$E_{A}$ & Austenite elasticity & $\mathrm{MPa}$ & 20700 \\
$\nu$ & Poisson's ratio & & 0.33 \\
$E_{M}$ & Martensite elasticity & $\mathrm{MPa}$ & 11700 \\
$\rho$ & Density & $\mathrm{kg} / \mathrm{m}^{3}$ & 6450 \\
$K_{A}$ & Thermal conductivity & $\mathrm{w} /(\mathrm{m} . \mathrm{K})$ & 18 \\
$C_{A}$ & Austenite specific heat & $\mathrm{J} /(\mathrm{kg} \cdot \mathrm{K})$ & 320 \\
$\alpha_{A}$ & Austenite thermal expansion coeff. & $1 / \mathrm{K}$ & $11 \times 10^{-6}$ \\
$\alpha_{M}$ & Martensite thermal expansion coeff. & $1 / \mathrm{K}$ & $6.6 \times 10^{-6}$ \\
$\rho s_{A}$ & Stress influence coefficient for austenite & $\mathrm{MPa} / \mathrm{K}$ & $-0.1705 \times 10^{6}$ \\
$\rho s_{M}$ & Stress influence coefficient for martensite & $\mathrm{MPa} / \mathrm{K}$ & $-0.905 \times 10^{6}$ \\
$M_{f}$ & Martensite finish temperature & $\mathrm{K}$ & 287 \\
$M_{s}$ & Martensite start temperature & $\mathrm{K}$ & 291 \\
$A_{s}$ & Austenite start temperature & $\mathrm{K}$ & 293 \\
$A_{f}$ & Austenite finish temperature & $\mathrm{K}$ & 297 \\
\hline
\end{tabular}

this study to set up the material properties. The material property choice of the stents is based on the heat treatment results of the NiTi [30].

\subsection{Boundary conditions and meshing}

FE model must be replaced by the actual boundary condition to ensure its practicality for the stent. Given the superelastic properties of NiTi stent, the used displacement manner was suitable. The standard tests of stent behavior include crimping and crushing. To carry out a crimping test between the stent and the crimper in shrinkage and extension steps, there was a surface-to-surface contact. The surface contact between the crimper and the stent was supposed to be frictionless. The crimper was subjected to a radial displacement and, then, the stent restored its primary form after removing the displacement. The diameter of the stent was reduced by 40 and $50 \%$ when the crimper was applied. To carry out the crushing test, the contact between the stent and planes was motivated [29]. The stent was positioned on two rigid parallel planes in the $Y$ orientation. The distance between planes was equal to the stent exterior diameter in the crushing test. This study supposed that the surface contact 


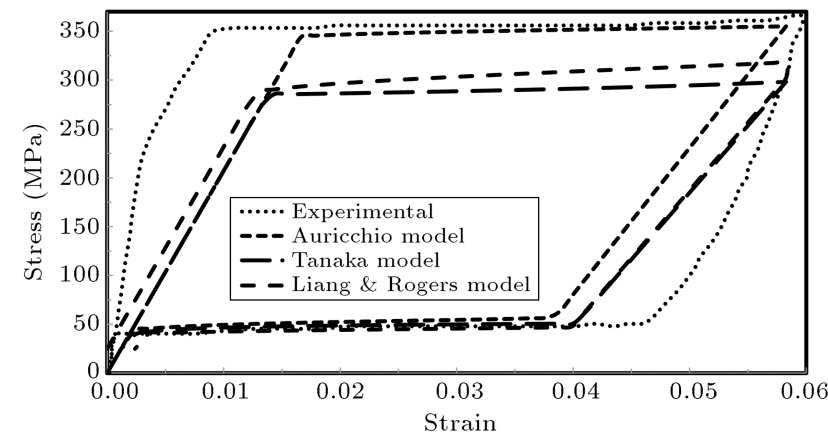

Figure 2. Calculation comparison of Auricchio's theory and models of Tanaka, Liang, and Rogers with empirical data achieved for NiTi sample shown in Tables 1 and 2.

between planes and stent was frictionless. A penalty method was applied to resistant boundaries. At first, the stent's diameter was reduced by 70 and $90 \%$ in the Y direction. Since the stent was characterized by natural, symmetrical axes, one-fourth of it was studied only. Ambient temperature was assumed to be $37^{\circ} \mathrm{C}$ to act out as the body temperature. Hypermesh (Altair ${ }^{\circledR}$ Hypermesh $^{\circledR}$ v. 6.0) was employed to mesh the models due to the meshing difficulties triggered by a tiny section of the NiTi wire and comparatively difficult geometrical stents. Mesh parameters of NiTi wire stent are shown in Table 3. Mesh density is characterized by 120 elements and 1010 nodes per $\mathrm{mm}^{2}$. Because of the non-convergence of the running program, C3D8I (incompatible mode eight-node brick) element was used instead of the element C3D8 for solving shear locking, bending, and contact of the stent. The application of the element C3D8I shows good agreement with the experimentally measured responses for the Z-shaped TAA NiTi wire stent samples.

\section{Results and discussion}

To assess TAA NiTi stents, numerous parameters including superelastic hysteresis, Chronic Outward Force (COF), Radial Resistive Force (RRF), plateau stress, stress, and strain need to be controlled. On the other hand, NiTi stents that exhibited a complete superelastic hysteresis loop, the lowest COF, the highest RRF, higher strain, and lower stress on the stent had acceptable mechanical performance [4246]. RRF and COF are schematically illustrated in Figure 3 as a function of the superelastic hysteresis

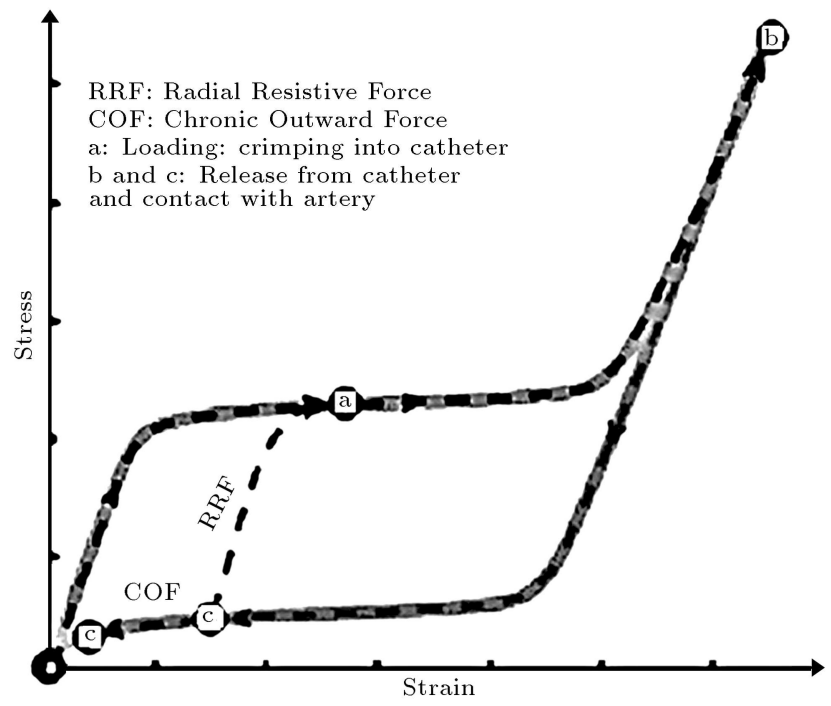

Figure 3. Superelastic hysteresis loop related to Radial Resistive Force (RRF) and Chronic Outward Force (COF).

loop. The stent is first crimped by two inflexible planes or crimpers (Figure 3; paths a and b). Then, it is deployed so that it can reach stress stability with the blood vessel or duct at point $\mathrm{c}$. The unloading curve $(\mathrm{COF})$ is used to control the force that opposes the blood vessel, and the loading curve (RRF) is used to control the force-resisting deformation. Generally, the stent designer attempts to design stents with the highest RRF (higher loading plateau stress) as probable and lowest COF (lower unloading plateau stress) as probable. Additionally, two specific topics should be booked into deliberation: (a) The stents showed acceptable superelastic performance and (b) the stents should be in the fracture-safe zone $[47,48]$. Based on the findings in this field $[49,50]$, increasing the angle between stent parts and the strain applied to the stent and increasing the inner stent diameter led to its suitable performance. This study showed that the high strain applied to the NiTi stent (crimping and crushing) improved mechanical performance.

\subsection{Assessing the mechanical performance of NiTi stent under crimping}

The designed Z-shaped TAA NiTi wire stent is illustrated in Figure 1. The Maximum Von Misses Stress (MVMS) and Maximum Principal Strain (MPS) of NiTi stent resulted in $40 \%$ and $50 \%$ crimping, as

Table 3. Mesh parameters of TAA NiTi stent during crimping and crushing.

\begin{tabular}{cccc}
\hline Material & Element type & Number of elements & Number of nodes \\
\hline Stent with 6 bends & C3D8I & 14400 & 18900 \\
Crimper & SFM3D4 & 206275 & 207390 \\
Stent with 6 bends & C3D8I & 14400 & 18974 \\
Rigid plane & R3D4 & $\mathbf{1 1 2 0}$ & 11502 \\
\hline
\end{tabular}


Table 4. Stress and strain results of the TAA stent under crimping.

\begin{tabular}{cccc}
\hline Stent performance & MVMS (MPa) & MPS & Strain limit \\
\hline $40 \%$ crimping & 412 & 0.01973 & 0.08 \\
$50 \%$ crimping & 401.8 & 0.02616 & 0.08 \\
\hline
\end{tabular}

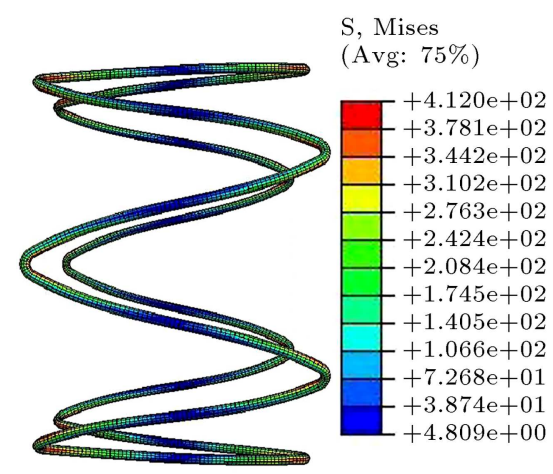

(a)

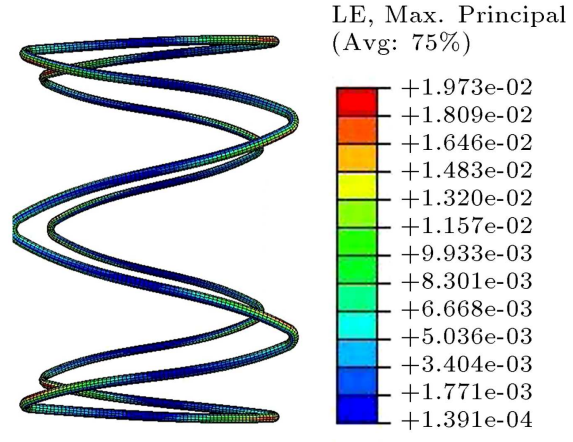

(b)

Figure 4. Results of $40 \%$ crimping of the TAA stent shown in Figure 1: (a) MVMS and (b) MPS.

shown in Table 4 and Figures 4-6. Table 4 and Figures 4-6 summarize the computational results of the stents shown in Figure 1(b), which are crimped in performance. The stents should perceive SIM behavior of the stress-strain curve to show appropriate superelastic behavior. The MVMS and MPS at $40 \%$ crimping show elastic behavior. Given that these stents failed to exhibit superelastic behavior, they were not appropriate for the TAA application. Consequently, according to Figures 4 and 6 , the desired superelastic behavior was not realized with NiTi stents at $40 \%$ crimping. Comparison of results indicates that the reduction of the MVMS from $412 \mathrm{MPa}$ to $401 \mathrm{MPa}$ led to a minor increase in the MPS from 0.01973 to 0.02616 . The increasing ratio is about $33 \%$. By increasing the crimping from $40 \%$ to $50 \%$ (indeed, higher percentage radial strain exerted on the NiTi stent), as shown in Table 4 and Figures 4,5 , and 6 , it is evident that MVMS on the internal curvature of NiTi stent at $40 \%$ crimping was greater than that at $50 \%$ crimping; the latter was preferred to the former in terms of the mechanical performance of these TAA NiTi stents. The MPS on the internal curvature of the NiTi stent at $40 \%$ crimping was lower than that at $50 \%$ crimping; the latter possessed better dynamic motion and was more coordinated with the artery circumstance. Moreover, according to Figures 5 and 6 , NiTi stent showed superelastic behavior because of increase in crimping up to $50 \%$. In addition, according to the assessment standards of the NiTi stent and the findings of other studies, NiTi stent was safe against mechanical loading $[8,11,43,49,50]$. Hence, given the mechanical

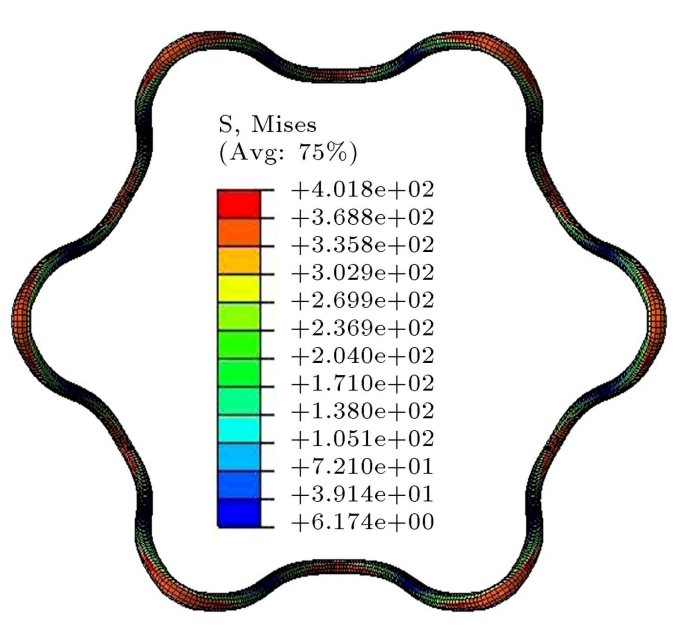

(a)

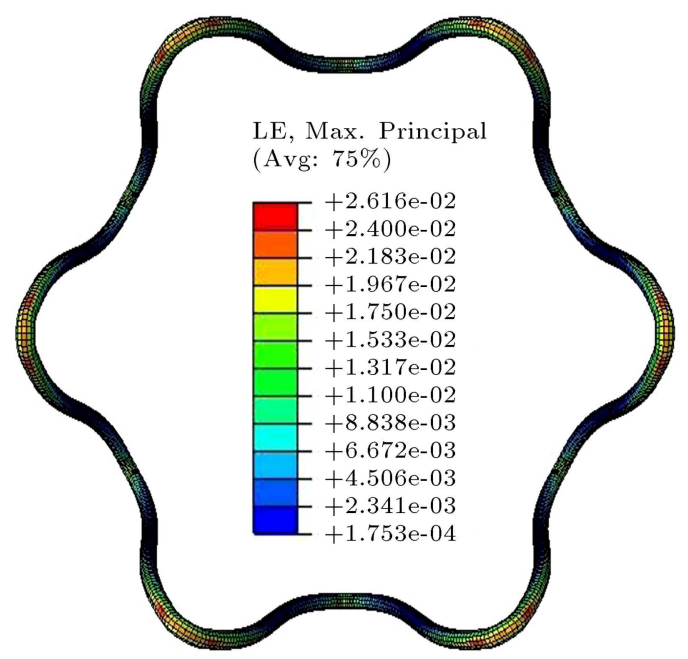

(b)

Figure 5. Results of $50 \%$ crimping of the TAA stent shown in Figure 1: (a) MVMS and (b) MPS. 


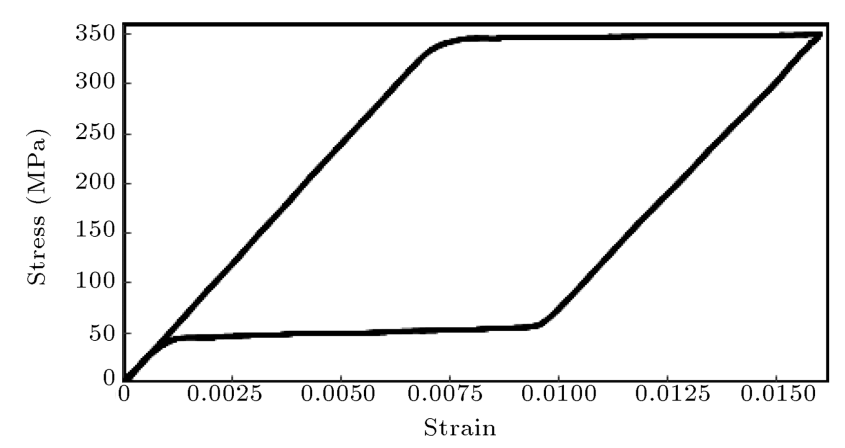

Figure 6. Results of superelasticity behavior plotted in $50 \%$ crimping on NiTi stent shown in Figure 1 (NiTi stent did not show superelasticity behavior in $40 \%$ crimping).

standards of NiTi stents and regarding Figure 6, they exhibited better mechanical performance by applying $50 \%$ crimping first owing to the superelastic behavior and because of appropriate $\mathrm{COF}$, proper RRF, high transformation strain, complete superelastic hysteresis, less stress distribution, and high strain distribution on the internal curvature of the NiTi stent. Moreover, according to Table 4, the MPS for $40 \%$ crimping is $1.973 \%$, which is considerably lower than the crucial verge strain value limit of $8 \%$, while $50 \%$ crimping has an MPS value of $2.616 \%$, which is considerably lower than its crucial verge value of strain limit of $8 \%$. Therefore, based on the assessment standards of the $\mathrm{NiTi}$ stent and the observation data of other studies, NiTi stent was safe against mechanical loading $[7-9,47,48]$.

\subsection{Assessing mechanical performance of NiTi stent under crushing}

The designed Z-shaped TAA NiTi wire stent is shown in Figure 1. MVMS and MPS of NiTi induced by $70 \%$ and $90 \%$ crushing on the NiTi stent are shown in Table 5 and Figures 7-9. Computational results of the stent, shown in Figure 1(b), which are crushed in performance, are displayed in Table 5 and Figures 7-9. This paper first presents the results of applying $70 \%$ crushing according to standards [8] and, then, shows the results of applying $90 \%$ crushing. Comparison of results reveals that increase in the MVMS from 387.7 $\mathrm{MPa}$ to $443.4 \mathrm{MPa}$ increases the MPS from 0.01484 to 0.03009 insignificantly. This increasing ratio is about $102 \%$. The MVMS and MPS at $70 \%$ crushing in Table 5 and Figures 7 and 9 showed a very small hysteresis loop of superelastic behavior. As a result, this NiTi stent was not appropriate for the TAA application. With respect to the increase in crushing from $70 \%$ to $90 \%$ (indeed, higher percentage of axial strain applied to the NiTi stent), the MVMS on the internal curvature of NiTi stent at $70 \%$ crushing was smaller than that at $90 \%$ crushing; the former was preferred to the latter in terms of the mechanical properties of designing these NiTi stents for the TAA applications. The MPS on the internal curvature of the NiTi stent at $70 \%$ crushing was lower than that at $90 \%$ crushing; the latter possessed superior dynamic gesture and was in better harmony with the artery circumstance. Moreover, the NiTi stent showed appropriate superelastic behavior. It was noticeable that the NiTi stent exhibited superelastic behavior under both conditions. Therefore, according to Figures 7 and 9 and based on the NiTi stent at $70 \%$ crushing, the desired superelastic behavior was not achieved because of low loop associated with superelastic behavior. However, appropriate superelastic behaviors were observed under $90 \%$ crushing. Moreover, according to the evaluation standards of the NiTi stent and in agreement with other studies, NiTi stent was safe against mechanical loading $[8,11,43,49,50]$. As a result, since the NiTi stents showed favorable mechanical standards, as shown in

Table 5. Stress and strain results of the TAA stent under crushing.

\begin{tabular}{cccc}
\hline Stent performance & MVMS (MPa) & MPS & Strain limit \\
\hline $70 \%$ crushing & 388 & 0.01484 & 0.08 \\
$90 \%$ crushing & 443 & 0.03009 & 0.08 \\
\hline
\end{tabular}

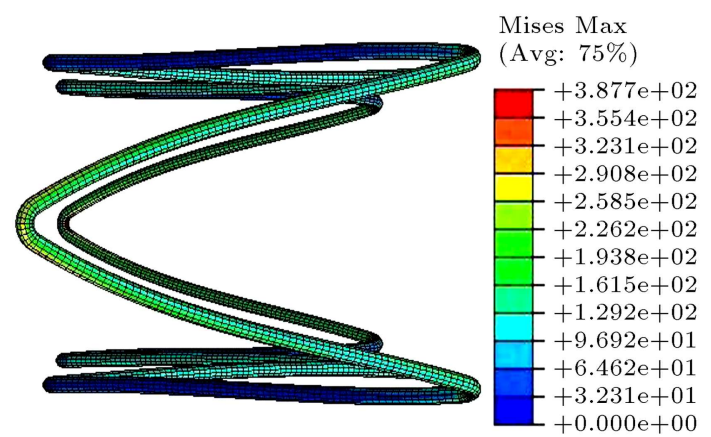

(a)

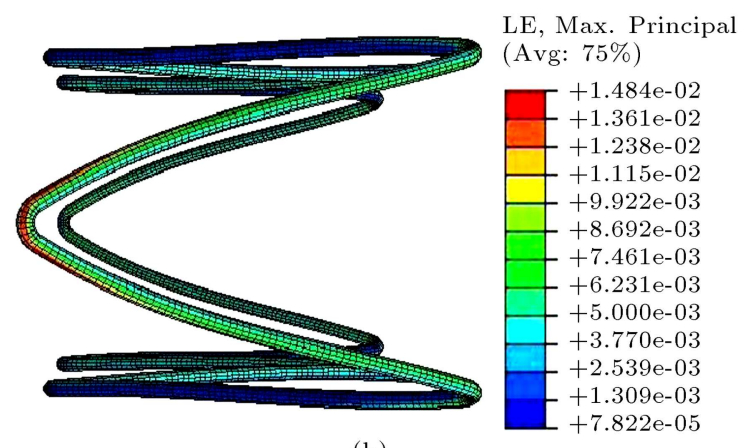

(b)

Figure 7. Result of $70 \%$ crushing of the TAA stent shown in Figure 1: (a) MVMS and (b) MPS. 


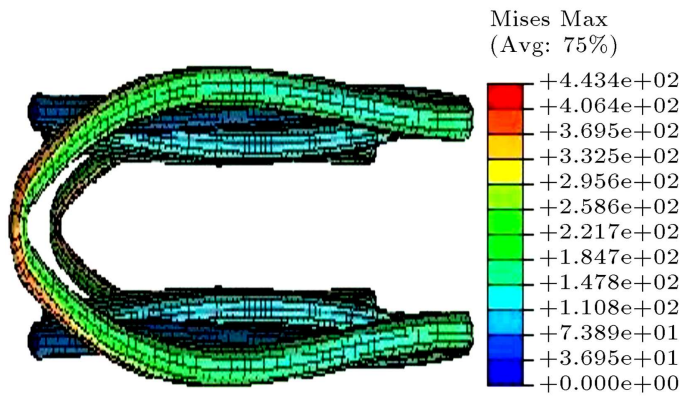

(a)

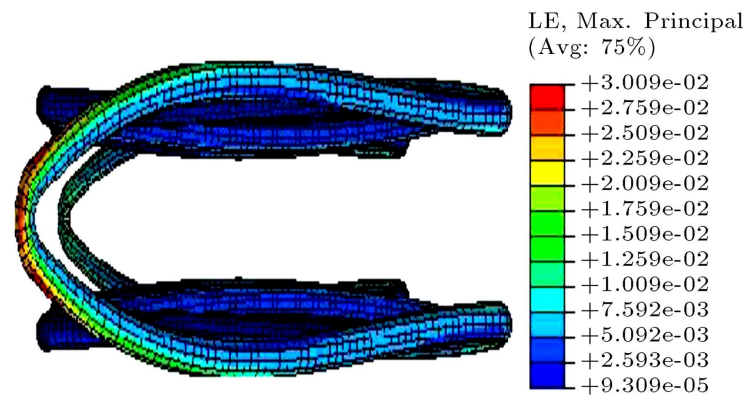

(b)

Figure 8. Result of $90 \%$ crushing of the TAA stent shown in Figure 1: (a) MVMS and (b) MPS.

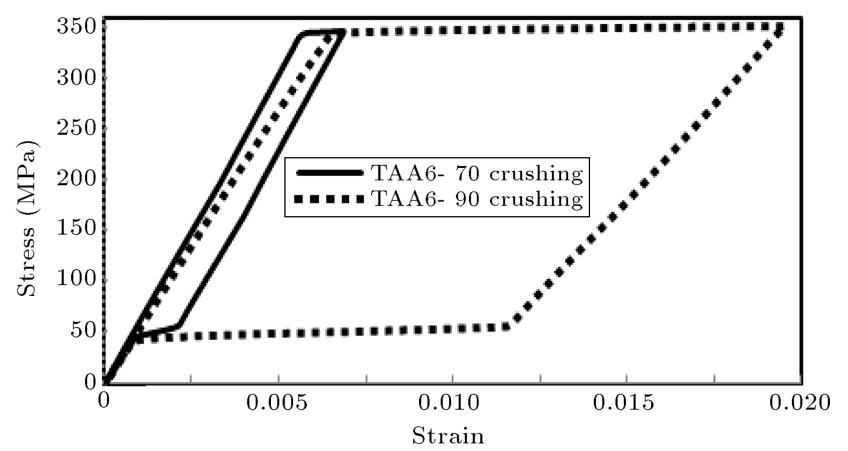

Figure 9. Results of superelastic behaviors plotted in $70 \%$ and $90 \%$ crushing on NiTi stent shown in Figure 1.

Figure 9, the NiTi stents revealed better mechanical performances by applying 90\% crushing owing to lower COF, higher RRF, higher transformation strain, complete superelastic hysteresis, and higher strain on the internal curvature of the NiTi stent. Moreover, according to Table 5, the MPS under $70 \%$ crushing is $1.484 \%$, which is considerably lower than the crucial verge strain value limit of $8 \%$, while $90 \%$ crushing has an MPS value of $3.009 \%$, which is considerably lower than the crucial verge strain value limit of $8 \%$. As a result, according to the appraisal standards of the $\mathrm{NiTi}$ stent and the observation data of other studies, the stent was safe against mechanical loading $[7-9,47,48]$.

\section{Limitations}

Material nonlinearity, nonlinear geometry, contacts, buckling, and bending make the simulation complicated. Further, it is predicted that stents will have selfcontact during crimping and crushing process, which can by itself add extra stress on the stent. However, this study ignored these types of stress due to the stent's superelastic behavior [51]. Undoubtedly, further experiments and simulation of arteries stenosis degree are required to draw a complete end. Moreover, further experiments and simulations are required with respect to plaque characterization, blood pressure, friction, blood vessel stenosis degree, graft, and residual stresses in blood pressure.

\section{Conclusion}

The paper investigated the impacts of crimping and crushing on the mechanical performance of Z-shaped NiTi wire stents. NiTi stent with $50 \%$ crimping exhibited good mechanical performance because of the appropriate Chronic Outward Force (COF), proper Radial Resistive Force (RRF), complete superelastic hysteresis, and lower stress distribution on the NiTi stent. Moreover, NiTi stent with $90 \%$ crushing showed desirable mechanical performance because of lower COF, higher RRF, upper transformation strain, and greater strain distribution on the NiTi stent.

\section{Acknowledgment}

The research conducted by the authors has been funded by the Deputy of Research and Technology of Arak University under Grant Number 92.9835(92.10.17). The authors are very grateful to Deputy of Research and Technology of Arak University.

\section{References}

1. Duerig, T., Tolomeo, D., and Wholey, M. "An overview of superelastic stent design", Min Invas Ther and Allied Technol, 9(3/4), pp. 235-246 (2000).

2. Stoeckel, D., Pelton, A.R., and Duerig, T. "Selfexpanding Nitinol stents: material and design considerations", Eur Radiol, 14, pp. 292-301 (2004).

3. Matsui, S.O., Terayama, N., and Kobayashi, S. "Clinical application of a curved nitinol stent-graft for thoracic aortic aneurysms", Endovc Ther, 10, pp. 2028 (2003).

4. Davies, J.E. "Endovascular repair of descending thoracic aortic aneurysm: review of literature thoracic", Cardiovc Surg, 21, pp. 341-346 (2009).

5. Canic, S., Ravi-Chandar, K., and Krajcer, Z. "Mathematical model analysis of wall stent and AneuRx dynamic responses of bare-metal endoprosthesis compared with those of stent-graft", Tex Heart. I. J, 32, pp. 502-506 (2005).

6. Patrick, B., Snowhill, B., John, L., Randall, L., and Frederick, H. "Characterization of radial forces in $\mathrm{Z}$ 
stents", Investigative Radiology, 36(9), pp. 521-530 (2001).

7. Whitcher, F.D. "Simulation of in vivo loading conditions of Nitinol vascular stent structures", Comput. Struct, 64(5-6), pp. 1005-1011 (1997).

8. Petrini, L., Migliavacca, F., Massarotti, P., Schievano, S., Dubini, G., and Auricchio, F. "Computational studies of shape memory alloy behavior in biomedical applications", J. Biomech. Eng, 127, pp. 716-725 (2005).

9. Kleinstreuer, C., Li, Z., Basciano, C., Seelecke, S., and Farber, M. "Computational mechanics of Nitinol stent grafts", J. Biomech, 41, pp. 2370-2378 (2008).

10. Beule, M., Cauter, S., Mortier, P., Loo, D., Impec, R., Verdonck, P., and Verhegghe, B. "Virtual optimization of self-expandable braided wire stents", Med. Eng, 31, pp. 448-453 (2009).

11. Silber, G., Alizadeh, M., and Aghajani, A. "Finite element analysis for the design of self-expandable Nitinol stent in an artery", Int. J. Energy. Tech, 2(19), pp. 1-7 (2010).

12. Merwe, H.V.D., Reddy, B.D., and Zilla, P. "A computational study of knitted Nitinol meshes for their prospective use as external vein reinforcement", $J$. Biomech, 41, pp. 1302-1309 (2008).

13. Fortier, A., Gullapalli, V., and Mirshams, R. "Review of biomechanical studies of arteries and their effect on stent performance", IJC Heart \& Vessels, 4, pp. 12-18 (2014).

14. Auricchio, F., Conti, M., Morganti, S., and Reali, A. "Simulation of transcatheter aortic valve implantation: a patient-specific finite element approach", Comput Methods Biomech Biomed Engin, 17(12), pp. 13471357 (2014).

15. Pauck, R.G. and Reddy, B.D. "Computational analysis of the radial mechanical performance of poly-L-lactic acid (PLLA) coronary artery stents", Med. Eng \& Phy, 37, pp. 7-12 (2015).

16. Jung, T. and Kim, J.Y. "Finite element structural analysis of self-expandable stent deployment in a curved stenotic artery", J. Mech. Sci and Tech, 30(7), pp. 3143-3149 (2016).

17. Guerchais, R., Scalet, G., Constantinescu, A., and Auricchio, F. "Micromechanical modeling for the probabilistic failure prediction of stents in high-cycle fatigue", J. Fatigue, 87, pp. 405-417 (2016).

18. Bressloff, N.W., Ragkousis, G., and Curzen, N. "Design optimisation of coronary artery stent systems", An. Biomed. Eng., 44, pp. 357-367 (2016).

19. Altnji, H., Bou-Saïd, B., and Walter, H. "Morphological and stent design risk factors to prevent migration phenomena for a thoracic aneurysm: A numerical analysis", Med. Eng. Phys, 37, pp. 23-33 (2015)

20. Nathan, A., Kobayashi, T., and Giri, J. "Nitinol selfexpanding stents for the superficial femoral artery", Interv. Card. Clin, 6, pp. 227-233 (2017).
21. Wang, R., Zuo, H., Yang, Y.M., and Yang, B. "Finite element simulation and optimization of radial resistive force for shape memory alloy vertebral body stent", J. Intel. Mater. Sys. Struct, 28(15), pp. 2140-2150 (2017).

22. Maleckis, K., Anttila, E., Aylward, P., and Poulson, W. "Nitinol stents in the femoropopliteal artery: A mechanical perspective on material, design, and performance", Ann. Biomed. Eng, 46(5), pp. 684-704 (2018).

23. Migliavacca, F., Petrini, L., Massarotti, P., Schievano, S., Auricchio, F., and Dubini, G. "Stainless and shape memory alloy coronary stents, a computational study on the interaction with the vascular wall", Biomech. Model. Mechanobiol, 2(4), pp. 205-217 (2004).

24. Terriault, P., Brailovski, V., and Gallo, R. "Finite element modeling of a progressively expanding shape memory stent", J. Biomech, 39(15), pp. 2837-44 (2006).

25. Auricchio, F., Conti, M., Beule, M., Santis, G., and Verhegghe, B. "Carotid artery stenting simulation: From patient-specific images to finite element analysis", Med. Eng. Phys, 33, pp. 281-289 (2011).

26. Lorenzo, V., Díaz-Lantada, A., and Lafont, P. "Physical ageing of a PU-based shape memory polymer: Influence on their applicability to the development of TAA devices", Mater \& Des, 30, pp. 2431-2434 (2009).

27. Elaraby, A. and Moratal, D. "A generalized entropybased two-phase threshold algorithm for noisy medical image edge detection", Sci. Iranica, D, 24(6), pp. 3247-3256 (2017).

28. Zendehbudi, G.R. "Effects of non-uniform wall properties on stress distribution in an abdominal aortic aneurysm, considering nonlinear constitutive equations", Sci. Iranica, B, 21(3), pp. 620-627 (2014).

29. Nematzadeh, F. and Sadrnezhaad, S.K. "Effects of material properties on mechanical performance of Nitinol stent designed for femoral artery: Finite element analysis", Scientia Iranica, 19, pp. 1564-1571 (2012).

30. Liu, X., Wang, Y., Yang, D., and Qi, M. "The effect of ageing treatment on shape-setting and superelasticity of a Nitinol stent", Mater. Charact., 59, pp. 402-406 (2008).

31. Lubliner, J. and Auricchio, F. "Generalized plasticity and shape memory alloy", Int. J. Solids and Struct, 33, pp. 991-003 (1996).

32. Auricchio, F. and Taylor, R. "Shape-memory alloys: modeling and numerical simulations of the finite-strain super elastic behavior", Compu. Meth. Appl. Mech. Eng, 143, pp. 175-94 (1996).

33. Auricchio, F. and Taylor, R. "Shape-memory alloys: Modeling and numerical simulations of the finite-strain superelastic behavior", Compu. Meth. Appl. Mech. Eng, 143(1-2), pp. 175-194 (1997).

34. Rebelo, N., Walker, N., and Foadian, H. "Simulation of implantable stents", In Abaqus User's Conference, 143, pp. 421-34 (2001). 
35. Conti, M., Beule, M., Mortier, P., Loo, D., Verdonck, P., Vermassen, F., Segers, P., Auricchio, F., and Verhegghe, B. "Nitinol embolic protection filters: design investigation by finite element analysis", J. Mater. Eng. Perform, 18, pp. 787-792 (2009).

36. Auricchio, F., Coda, A., Reali, A., and Urbano, M. "SMA numerical modeling versus experimental results: parameter identification and model prediction capabilities", J. Mater. Eng. Perform, 18, pp. 649-654 (2009).

37. Arghavani, J., Auricchio, F., Naghdabadi, R., and Sohrabpour, S. "A 3-D phenomenological constitutive model for shape memory alloys under multiracial loadings", Int. J. Plasticity, 26, pp. 976-991 (2010).

38. Khalil Allafi, J., Ren, X., and Eggeler, G. "The mechanism of multistage martensite transformation in aged Ni-rich NiTi shape memory alloys", Acta Mater, 50, pp. 793-803 (2002).

39. Prince, A.G., Quarini, G.L., and Morgan, J.E. "Thermomechanical response of $50.7 \% \mathrm{Ni}-\mathrm{Ti}$ alloy in the pseudoelastic regime", Mater. Sci. Tech, 19, pp. 561565 (2003).

40. Boyd, J.G. and Lagoudas, D.C. "A thermodynamical constitutive model for shape memory materials", Part I. The Monolithic Shape Memory Alloy, 12, pp. 805842 (1996).

41. Qidwai, M.A. and Lagoudas, D.C. "Numerical implementation of a shape memory alloy thermomechanical constitutive model using return mapping algorithms", Int. J. Num. Meth. Eng, 47, pp. 1123-1168 (2000).

42. Koop, K., Lootz, D., Kranz, C., Momma, C., Becher, B., and Kieckbusch, M. "Stent material nitinol - determination of characteristics and component simulation using the finite element method", Prog. in Biomed. Research, 6(3), pp. 237-245 (2001).

43. Gong, X., Duerig, T., Pelton, A., Rebelo, N., and Perry, K. "Finite element analysis and experimental evaluation of superelastic Nitinol stents", In Proceedings of the International Conference on Shape Memory and Superelastic Technology Conference - SMST (2003).

44. Gideon, V., Kumar, P., and Mathew, L. "Finite element analysis of the mechanical performance of aortic valve stent designs", Trends Biomater. Artif. Organs, 23(1), pp. 16-20 (2009).

45. Salaheldin, M., Zilla, S., and Franz, T.A. "Computational study of structural designs for a smalldiameter composite vascular graft promoting tissue regeneration", Cardiovascular Eng. Tech, 1(4), pp. 269-281 (2010).

46. Auricchio, F., Conti, M., Morganti, S., and Reali, A. "Shape memory alloy: from constitutive modeling to finite element analysis of stent deployment", CMES, 57(3), pp. 225-243 (2010).

47. Pelton, A.R., Schroeder, V., Mitchell, M., Gong, X., Barneya, M., and Robertson, S. "Fatigue and durability of Nitinol stents", J. Mech. Behav. Biomed. Mater, 1, pp. 153-164 (2008).
48. Santillo, M. "Fracture and crack propagation study of a superficial femoral artery Nitinol stent", Ms Thesis University of Pavia, Italy (2008).

49. Wang, R. and Ravi-Chandar, K. "Mechanical response of a metallic aortic stent - Part I: Pressure diameter relationship", J. Appl. Mech, 71, pp. 697-705 (2004a).

50. Wang, R. and Ravi-Chandar, K. "Mechanical response of a metallic aortic stent - Part II: A beam on elastic foundation model", J. Appl. Mech, 71, pp. 706-712 (2004b).

51. Wu, W., Qi, M., Liu, X., Yang, D., and Wang, W. "Delivery and release of Nitinol stent in carotid artery and their interactions: a finite element analysis", $J$. Biomech, 40(13), pp. 3034-40 (2007).

\section{Biographies}

Fardin Nematzadeh was born in Ardabil, Iran in 1976. He received his BS degree in Materials Science and Engineering from Sahand University of Technology, Tabriz, Iran in 1998, his MS degree in Materials Science and Engineering from Sharif University of Technology, Tehran, Iran in 2001, and his PhD degree in Materials Science and Engineering from Sharif University of Technology and Material and Energy Center (MERC), Tehran, Iran in 2012. He has joined the Materials Engineering Department of Arak University as an Assistant Professor since 2012. His main research interests include modeling and simulation in medical applications such as stent, shape-memory alloys, biomaterials, biomechanics, and joining methods. He has published more than 50 papers in international journals and conferences. Currently, he is a reviewer in many technical valid journals such as Journal of Intelligent Material Systems and Structures, Journal of Biomedical Materials Research Part B Applied Biomaterials and Computer Methods in Biomechanics and Biomedical Engineering.

Hossein Mostaan was born in Ahvaz, Iran, in 1985. He received his BS degree in Materials Science and Engineering from Sharif University of Technology, Tehran, Iran in 2007, his MS degree in Materials Science and Engineering from Isfahan University of Technology, Isfahan, Iran in 2010, and his PhD degree in Materials Science and Engineering from Isfahan University of Technology, Isfahan, Iran in 2014. He has joined the Materials Engineering Department of Arak University as an Assistant Professor since 2014. His main research interests include mechanical and physical of advanced materials, heat treatment of metals, welding metallurgy, and powder metallurgy. He has published more than 50 papers in international journals and conferences. 